Published in the Journal of Banking and Finance 30 (9), September 2006: 2579-2597

\title{
What Explains Household Stock Holdings?
}

\author{
Pauline Shum and Miquel Faig ${ }^{\dagger}$ \\ York University and University of Toronto
}

October 4, 2005

\begin{abstract}
This is an empirical study of the determinants of stock holdings using data from the U.S. Survey of Consumer Finances from 1992 to 2001. There is a great heterogeneity in the way households form their portfolios. Stock ownership is positively correlated with various measures of wealth, age, retirement savings, and having sought financial advice. It is negatively correlated with holdings of alternative risky investments, such as investments in private businesses, and with the willingness to undertake non-financial investments in the future. While we can predict reasonably well who holds stocks, we have less predictive power about the share of stocks owned by those who hold positive amounts.
\end{abstract}

JEL: G11

Keywords: Portfolio choice, stock holdings, consumer finances.

${ }^{\dagger}$ Faig is with the Department of Economics at the University of Toronto. Shum is with the Schulich School of Business at York University. We thank Rong Li and Vlad Kyrychenko for excellent research assistance, two referees for their valuable comments, and SSHRC of Canada for financial support. 


\section{Introduction}

How do investors divide their wealth among different assets? What are the factors that influence the composition of an investor's optimal portfolio? During the last decade, asset allocation has re-emerged at the forefront of financial research. In part, this trend is due to the availability of new micro data, and in part it is due to the rise of practical interest in this branch of finance. This practical interest has grown with the importance of financial assets as a share of total assets. This share has climbed from 31.6 percent in 1992 to 42 percent in 2001 (see Aizcorbe, Kennickell and Moore, 2003). Furthermore, the interest of portfolio theory has also grown with the concerns over the management of retirement wealth. With the rise in popularity of directed retirement accounts, individuals are finding it necessary to educate themselves in this area. ${ }^{1}$ This necessity will become ever more pressing if President Bush's proposed private Social Security program becomes a reality. In this paper, we contribute to the theory of portfolio choice by examining the empirical determinants of stock holdings. In our study, we use the broad U.S. Survey of Consumer Finances (SCF) from 1992 to 2001, and explore some information little explored in earlier contributions.

The SCF provides a rich source of information on the financial characteristics of U.S. households. Detailed information is collected on household assets and liabilities, as well as accompanying household characteristics such as demographics, labour force activities, income,... etc. The survey is conducted every three years. In our analysis, we employ the four most recent editions of the survey that are currently available: 1992, 1995, 1998, and 2001. Our analysis of this rich set of data complements the existing literature in the following ways. First, the recently released survey of 2001 provides an interesting look at stock holdings after the bull market years of the late 1990's. Second, we have information on the overall portfolios held by households that are representative of the U.S. population, as opposed to relatively narrow subsets as in several recent studies. (Agnew,

1 Self directed tax-deferred accounts, for example, represent a substantial portion of retirement wealth in the U.S. See Bergstresser and Poterba (2002). 
Balduzzi, and Sundén, 2003, focus on 401(k) accounts of one company, Odean, 1999, and Barber and Odean, 2001, focus on discount brokerage accounts of one financial institution.) Third, our data set allows us to include a more comprehensive set of explanatory variables than in previous studies. For example, Ameriks and Zeldes (2001) focus primarily on the distinction among the age, time and cohort effects. Barber and Odean (2001) focus on gender and marital status. Agnew, Balduzzi, and Sundén (2003) focus on age, gender, marital status, salary and job tenure. Because the SCF contains information on many household characteristics, we add variables such as non-financial investments (e.g., real estate, private business), motives for saving, and the use of professional investment advice.

The main insights we learn from our analysis are as follows:

Households have continued to increase their stock holdings in 2001 relative to earlier surveys. Despite the end of the bullish stock market of the nineties, households in 2001 were not only more likely to hold stocks than in earlier surveys, but also those who held stocks increased on average the equity share in their financial portfolios. Both the increase in the participation rate and the increase in the average equity share are robust to the control for other household characteristics.

The distribution of households by the fraction of stocks held in their overall portfolios is much less bimodal than the distributions reported by Ameriks and Zeldes (2001) and Agnew, Balduzzi, and Sundén (2003) in 401(k) accounts. Therefore, the two extreme modes at zero and at 100 percent stocks documented in these earlier studies do not reflect extreme overall portfolio formation. Instead, they may reflect an attempt to minimize transaction costs and tax liabilities, or reflect the set of investment choices available in 401(k) plans, which can have a strong equity bias.

Saving motives are important for predicting if a household holds stocks or not. Saving for education bills, household purchases, and retirement increases the likelihood of stock ownership. Meanwhile, saving to invest in a private business enterprise reduces the likelihood of stock ownership. 
One of the new variables we study is professional investment advice. Households who sought professional investment advice are more likely to hold stocks. This is consistent with the view that an important barrier to holding stocks is the lack of financial sophistication to do so successfully. However, many households who sought professional advice did not actually end up investing in stocks. Likewise, the distribution of households by their share of equity in the financial portfolio is little affected by having sought professional advice or not. Therefore, we conclude that the barriers to enter the stock market are not easily mitigated by professional advice, and that other important factors are at play. ${ }^{2}$

We observe a hump-shaped age effect in both stock ownership and equity shares in portfolios. The likelihood of stock ownership, conditional on a host of other explanatory variables, increases with age until age 61, while conditional equity shares peak at around age 50 .

The rest of the paper is organized as follows. In Section II, we document the distribution of households by the fraction of stocks in their financial portfolios. In Section III, we describe the explanatory variables, the sample selection process, and the method of estimation. In Section IV, we present a probit analysis of who owns stocks. In Section V, we analyze the determinants of the fraction of stocks held in the portfolio conditional on stock ownership. In Section V, we study a Tobit model where the decision to hold stocks and the fractions held are decided simultaneously. A summary section concludes the paper.

\section{Distributions of stock holdings}

To get a feel of the portfolio data in the SCF, we begin by documenting the distributions of stock holdings among U.S. households in the four surveys conducted in 1992, 1995, 1998,

2 The relevance of professional financial advisors is also addressed by Alexander, Jones, and Nigro (1997), who examine a survey of mutual funds investors. They find that 21.5 percent of investors cite professional financial advisors as the best source of information. By comparison, 32.3 percent cite financial publications and prospectuses. They also find that many investors lack basic knowledge on financial matters regardless of having sought professional advice or not. 
and 2001. A household consists of an economically dominant single individual or couple and all other persons in the household who are financially dependent on that individual or couple. A financially self-sufficient grandparent, for example, would be excluded. In order to focus on households who can construct meaningful portfolios, we apply the following sample selection criteria in all the tables that follow. We include only households with 1) financial net worth (financial assets $^{3}$ minus financial debt ${ }^{4}$ ) greater than or equal to $\$ 1000$, 2) positive total (financial and physical) net worth, and 3) positive labour income. We also eliminate outliers based on several ratios of assets to total networth (details are provided in the next section). The distributions are reported in Tables 1 to 4 below.

[Table 1]

In Table 1, we report the distribution of households by the ratio of stocks held in a particular category over the total value of their financial assets. We refer to the latter as the financial portfolio. "Total stock holdings" is an all inclusive category. It includes directly-held stocks, stocks in mutual funds, individual retirement accounts, thrift-type defined contribution plans, and other managed assets with equity interest such as annuities and trusts. The other three specific categories we consider are: retirement accounts, directly-held stocks, and mutual funds. "Retirement accounts" include, individual retirement accounts such as IRAs and Keoghs, as well as defined contribution plans such as thrift and 401(k) accounts. The self-explanatory category "directly-held stocks" does not include stocks held in retirement accounts. Finally, "stocks in mutual funds" is the value of stocks in mutual funds that are held outside retirement accounts.

As expected, we observe in Table 1 an increase in stock holdings over time as the

\footnotetext{
3 Financial assets include cash (checking and saving accounts, call accounts at brokerages, and money market accounts), stocks and bonds either directly held or held in mutual funds, IRAs and thrift-type accounts, cash value of whole life insurance, other managed assets (trusts, annuities, and managed investment accounts), and other financial assets (loans, future proceeds, royalties, futures, non-public stock-deferred compensation, and money in hand).

4 Financial debt, as defined by the Federal Researve includes liabilities such as credit card balance, line of credit, and other loans not related to fixed assets.
} 
distributions gradually shift away from zero. While the change in directly-held stocks is marginal, equity shares in retirement accounts have increased substantially from 1992 to 2001. This general shift away from zero in all four categories in Table 1 persisted into the 2001 survey, after the end of the bull market. In all four categories, the decline in the fraction of households holding no stocks from 1992 to 2001 is statistically significant at the five percent level. Also, households who invested more than 80 percent of their financial assets in stocks increased over these nine years from 6.59 percent to 18.46 percent. Again, this change is statistically significant at the five percent level.

Despite the shift away from zero stocks in all four surveys, there is a substantial fraction of households who held no stocks of any kind, and the great majority of households held no stocks either directly or through mutual funds outside retirement accounts. This is a puzzle for normative theories of portfolio choice. Given the observed equity premium and the observed riskiness of investing in the stock market, normative theories predict that for reasonable degrees of risk aversion, most households should invest most of their financial wealth in stocks, and possibly take leveraged positions. (See Curucuru, Heaton, Lucas, and Moore, 2004, Section 4).

Since households with very low holdings of financial assets or wealth are eliminated from our sample, the lack of participation in the stock market cannot be simply due to the lack of funds to invest. Several authors ${ }^{5}$ have attributed the low participation rate to barriers to entry, which include the cost of gathering information about investment strategies or obtaining financial advice. The last three editions of the SCF allows us to test a part of this explanation. Since 1995, the SCF has asked households if they have sought investment advice within the previous year. We focus on the role of professional investment advice, defined as investment advice from a banker, an accountant, a financial planner, or a broker. If the cost of obtaining this advice is the main factor discouraging households from participating in the stock market, the subsample of households who have sought

5 See, for example, Saito (1995), Basak and Cuoco (1998), Polkovnichenko (1998), Paiella (2001), and Vissing-Jorgensen (2004). 
professional advice should have a much smaller fraction of households with zero stocks. In Table 2, we show that this is not the case.

[Table 2]

In Table 2, we report the analogous distributions to those in Table 1, but only for households that have sought professional investment advice within the previous year. As one would expect, households who have sought investment advice generally have a higher participation rate in the stock market, particularly in 1995 and in 1998 where the differences are statistically significant at the five percent level. Those who participate also invest larger amounts. However, these effects are not large, so the overall distributions in Tables 1 and 2 are quite similar. In particular, in 2001, the fraction of households who had no stocks of any kind is the same for those who have sought professional financial advice and those who did not. In the same year, the fraction of households who held no stocks in each one of the other three categories is only marginally lower for the households who have sought professional financial advice. Therefore, professional financial advice as defined above is insufficient to break all the barriers to enter the stock market. Other barriers must remain to explain the low or non-participation of a sizable fraction of the population.

In Table 3, we report the distribution of households by the fraction of stocks they hold in two interesting subsets of the overall portfolio: retirement accounts and mutual funds. The sample for retirement accounts includes only households with at least one retirement account. Similarly, the sample for mutual funds accounts includes only households with at least one mutual funds account. Retirement accounts includes individual retirement accounts such as IRAs and Keoghs, as well as defined contribution plans such as thrift and 401(k) accounts. Mutual funds accounts do not include mutual funds held in retirement accounts.

[Table 3]

The two distributions in Table 3 are interesting. While the mass at zero in both categories is still large, there are two additional spikes in the middle and the upper tail of 
each distribution. Hence, the two most popular equity allocations in retirement accounts and mutual funds are zero and 100 percent, followed by (approximately) 50 percent. In earlier contributions, Agnew, Balduzzi, and Sandén (2003) and Ameriks and Zeldes (2002) have documented a bimodal distribution of equity allocations in retirement accounts (401(k)s and TIAA-CREF, respectively) with spikes at the two extremes. However, the fact that this bimodal distribution is not present in the overall financial portfolio as seen in Table 1 suggests that individuals do not necessarily seek extreme portfolios. Instead, individuals may be seeking to minimize tax liabilities or intermediation costs when they choose a "zero or one" share of equity in retirement accounts. The also popular 50-50 allocation is probably due to the simplicity of the rule, which among other things makes it an easy answer to the interviewer of the survey.

In Table 4, we restrict again the sample of households to those who sought professional investment advice, and we report the analogous distributions to those in Table 3. Overall, the distributions in Table 4 are quite similar to those in Table 3. In both tables the distributions are tri-modal with spikes at the two tails and the middle. In some years, households who sought professional investment advice tended to diversify their portfolios a little bit more than those who did not, but the differences between the two tables are quantitatively small, as they were the differences between Tables 1 and 2 .

[Table 4]

We tried relaxing the sample selection criteria with weaker filters or including all households (not shown). In all cases, the basic patterns in Tables 1 to 4 do not change. The main difference when all households are included is that the distributions are more skewed towards zero stock holdings. This difference is not surprising since we screen out low net worth households in our sample selection.

\section{Variables, sample selection, and estimation}

\section{a. Explanatory variables}


Our selection of explanatory variables is guided by the theoretical literature in asset allocation. We also make use of unique variables in the SCF, such as risk attitude, motives for saving, and investment advice. The set of explanatory variables are as follows:

1. Age and time: age, age ${ }^{2}$, time dummies for the 1995, 1998, and 2001 surveys

Several studies have documented the hump-shape relationship between equity holdings and age. ${ }^{6}$ (See, for example, Table 6 in Aizcorbe, Kennickell and Moore (2003) for a summary of the evidence from the 1992, 1995, 1998 and 2001 SCFs. Also, see Cocco, Gomes and Maenhout (2005) for possible theoretical rationales to explain this pattern.) To capture this nonlinear age effect, we use age and $\mathrm{age}^{2}$ in the regression. A caveat of calling this an "age" effect is that, as Ameriks and Zeldes (2001) suggest, the age variable likely captures both a time and a cohort effect. In the pooled regressions, we include a time dummy to see if there is a separate time effect. We expect that stock market participation and equity shares increased over time.

\section{Financial net worth}

We use financial net worth to control for financial wealth in the portfolio decision. Also, we include the square of financial net worth to account for possible nonlinearity in the relationship. For example, we may expect households to hold more stocks as financial net worth increases. However, households with very high financial net worth may be more averse to risk in their financial portfolios if their financial net worth is a significant part of their total wealth, which means that portfolio returns are highly correlated with consumption. We expect that stock market participation and equity shares increase with financial net worth.

3. Real estate: relative housing value, investment real estate

We control for ownership of real estate using two variables. One is housing value relative to total net worth, where housing refers to each household's primary residence.

\footnotetext{
6 By equity holdings, we are referring to the fraction of stocks in a household's financial portfolio. If other assets such as private businesses are included in the denominator, then the hump-shape pattern does not necessarily hold. See Heaton and Lucas (2000).
} 
The other is that value of investment real estate relative to total net worth. Housing is the largest investment of most households. It is an important source of income in the form of shelter services, as well as an important source of financial commitments such as mortgage payments, property taxes, repairs, and so on. In addition, real estate are fairly illiquid assets, in the sense they involve substantial transaction costs, which include taxes, commissions, and the cost of moving. We expect that stock market participation and equity shares decrease with stakes in real estate.

\section{Risk attitude}

There is a self-reported risk attitude variable in the survey, based on a hypothetical investment question on risk and return trade-off. This variable takes on four possible values, one to four. A larger number implies a higher degree of risk aversion. We expect that higher degree of risk aversion leads to lower stock participation rates and equity shares.

\section{Entrepreneurial risk: relative business value}

Some households in the surveys own private businesses. The latter is a proxy for entrepreneurial risk (Heaton and Lucas, 2000), and is also an example of personal illiquid projects that generate liquidity needs (Faig and Shum, 2002). We use private business value (which includes personal assets used as collateral for business loans) relative to total net worth as a proxy for these effects. We expect that stock market participation and equity shares decrease with stakes in private businesses.

\section{Labour income: $\log$ of labour income}

Labour income consists of wages, salaries, and professional income including farm income. We use the log of labor income in the regression to dampen the effects of extreme values. This variable can be interpreted as a measure of human capital (holding age and other characteristics constant). We expect that households with more human capital are less vulnerable to the risk of their financial portfolios, and hence are more likely to participate in the stock market, and hold a higher portion of their portfolio in equity. However, this effect is ambiguous in theory, because the riskiness of labour income generates background 
risk which works in the opposite direction.

\section{Saving motives}

In the SCF, there is also a section on miscellaneous opinion variables. The useful variables for our purpose are the questions on saving motives. Respondents are asked to choose from a list provided by the interviewer their top reasons for saving. These reasons proxy for the short-/long-term liquidity needs of each household. We group the list of reasons into eight categories. They are: (1) education (one's own, spouse's, children's, and grandchildren's), (2) invest in own home (purchase or renovate own home/cottage), (3) household purchases (appliances, furnishings, cars, special occasions, and hobby items), (4) travel (vacations, and time off), (5) invest in own business (purchase own business/farm and/or equipment for business/farm), (6) retirement (including burial expenses), (7) emergency (unemployment, illness, and "rainy" days), and (8) living expenses and bills (including tax and insurance bills, and other contractual commitments). We convert each category into a dummy variable, assigning the value one if a respondent chooses it as one of his/her top three reasons for saving, and zero otherwise.

We should emphasize that these saving motive dummies represent intentions to spend in the future, and are meant to capture household liquidity needs in our analysis. Variables such as "relative housing values", or "relative business values" discussed earlier, are dollar figures of actual holdings, and are meant to capture mainly the diversification aspect of portfolio choice. Hence, while these variables may sound related, they measure very different effects.

\section{Professional investment advice}

Beginning in the $1995 \mathrm{SCF}$, respondents to the survey are asked whether they have sought financial advice from a third party within the past year. Seeking financial advice should reduce the barrier to equity investment, and the resulted asset allocation may be more "predictable". To this end, we focus on the impact of professional investment advice. If the respondent has explicitly received investment advice from (1) an accountant, (2) a 
financial planner or broker, and (3) a banker, then the dummy variable for professional investment advice is set to one, and zero otherwise. One may argue that professional financial advice is an endogenous variable, in that households who want to invest in stocks may be more likely to seek professional advice. Hence, its coefficient in the regressions should be interpreted with care. In our sample, the fractions of households who sought professional investment advice are: 26 percent in 1995, 37 percent in 1998 and 36 percent in 2001. We expect that stock market participation is more likely if a household has sought professional investment advice.

\section{b. Sample selection}

Following Faig and Shum (2002), we impose the following criteria in our sample selection. First, since we are trying to analyze portfolio choice, we exclude households that do not have sufficient funds to form a reasonable portfolio. We exclude observations with financial net worth smaller than $\$ 1000$. We also screen out observations with zero or negative total net worth, particularly since this variable appears in the denominator of two explanatory variables. Second, we exclude households that report zero labour income. ${ }^{7}$ Third, we eliminate outliers in several explanatory variables: observations with a ratio greater than four in 1) housing value relative to net worth, 2) investment real estate relative to net worth, and 3) business value relative to net worth, are removed. Our filters combined eliminate 39.80 percent, 38.68 percent, 37.42 percent, and 33.98 percent of the sample in the 1992, 1995, 1998, and $2001 \mathrm{SCF}$, respectively. ${ }^{8}$

\section{c. Estimation}

7 Because of this exclusion, the average age of the households eliminated is around 3 years older than those we select. However, the impact it has on our variables of interest is small. For example, we tried estimating the model including households with zero labor income (without taking logs) and found similar results, except for the parameter estimate of labor income which becomes statistically insignificant.

8 Other authors in this literature have used more stringent sample selection rules. For example, Heaton and Lucas (2000) exclude households with less than $\$ 500$ in stock holdings, and those with less than $\$ 10,000$ of financial net worth. 
The SCF, compiled by the Federal Reserve Board, is based on a dual-frame sample design, incorporating both a standard multi-period national area-probability design and a list-sample design. The list sample is selected from a set of tax returns. It is intended to provide a disproportionate representation of wealthy households, who own a large percentage of skewed assets such as stocks, options, and antiques. To compensate for this unequal probability in the sample design and for failure to obtain an interview with some of the selected households, a set of sample weights is included in the data set.

Between 4,000 and 5,000 households are interviewed in person for each survey. The public data set of each survey consists of five implicates, as a result of the multiple imputation technique used to handle missing data. Some data may be missing because respondents are unable or unwilling to provide certain pieces of information. ${ }^{9}$ See Kennickell (1998) for a discussion of multiple imputation in the SCF. We utilize information contained in all five implicates. Using the Repeated-Imputation Inference (RII) technique described in Montalto and Sung (1996), we include both the within-imputation variance and the across-imputation variance in generating inferences. This estimation methodology takes into account the sample-selection bias in the SCF and incorporates the variability in the data due to missing information. ${ }^{10}$

\section{The decision to hold stocks: probit analysis}

We now consider the decision to participate in the stock market using probit regressions. In the next two sections, we deal with the decision on how large the equity exposure should be. In Table 5 below, we report the probit regression results for the pooled data from the

\footnotetext{
9 Imputation involves the 'filling in' of missing data with plausible values. Multiple imputation is a Monte Carlo technique in which the missing values are replaced by multiple simulated versions. In the case of the SCF, there are five such versions, or five such implicates.
}

10 To summarize briefly, the Repeated-Imputation Inference (RII) estimation technique analyzes each implicate separately using standard methods, and combine the results to produce estimates and confidence intervals that incorporate missing-data uncertainty. 
1992, 1995, 1998, and 2001 surveys. The dependent variable is equal to one if total stock holdings are positive, and zero otherwise.

[Table 5]

In Table 5, we observe that our probit regression is fairly successful in predicting who holds stocks. The percentage of accordant responses (or correct predictions) is 78 percent. Age affects the likelihood of stock ownership, and this effect is hump-shaped. Age increases the likelihood of holding stocks until age 61. Financial net worth also affects the likelihood of stock ownership in the same fashion. Stock market participation increases with financial net worth for most households, because the likelihood of owning stocks, holding everything else constant, does not peak until $\$ 209$ million. Further, the higher the degree of risk aversion, the less likely that a household would own stocks; while labour income increases this likelihood. The following saving motives lead to a significantly higher likelihood of stock ownership: education, household purchases, and with the largest coefficient, retirement. Meanwhile, households who save to invest in their own business avoid owning stocks. Stock ownership increased significantly both from 1995 to 1998, and from 1998 to 2001. Therefore, the increasing participation in the stock market observed in Section II is still present once we control for the other independent variables in the regression. We will elaborate on these results and relate them to the literature later.

Separate probit analyses of the four surveys, rather than the pooled data, reveal a qualitatively similar pattern. The explanatory variables that are statistically significant in at least two of the three surveys are: age, age $^{2}$, financial net worth, financial net worth $^{2}$, risk attitude, relative business value, log of labour income, and two saving motives: household purchases and retirement. In three of these separate regressions (1995, 1998, and 2001), we are able to include a dummy variable indicating whether a household sought professional investment advice. This question was not asked in 1992. Households that sought professional advice were more likely to participate in the stock market. The coefficient on this variable is strongly positive for 1995 and 1998, but it is not for 2001. 
This finding is consistent with our earlier analysis of Table 2 in Section II. The percentages of accordant responses are again satisfactory, and they have improved over time from 73 percent in 1992 to 83 percent in 2001. These results are reported in Table 6 below.

\section{[Table 6]}

The positive coefficients for labour income in the previous two tables are consistent with the predictions of calibrated versions of normative models of portfolio choice. Numerical simulations of these models show that for realistic parameters, consumption becomes less correlated with the return on the financial portfolio as human capital increases. (See, for example, Cocco, Gomes and Maenhout, 2005, who show in a life-cycle context labour income substitutes for risk-free asset holdings. See also Koo, 1995, Heaton and Lucas, 1997, Bertaut and Haliassos, 1997, Viceira, 2001, and Woolley, 2005 for related analyses.) Therefore, individuals who are well endowed with human capital benefit the most from owning stocks. This theoretical result implies not only a positive coefficient for labour income, but also that the likelihood of owning stocks should peak early in the life of an individual, which is when on average human capital peaks. However, the coefficients for age and age ${ }^{2}$ suggest that the conditional likelihood of stock ownership increases until the age of 61 . This late age for the peak of the conditional likelihood is consistent with the view that there are significant entry barriers to the stock market, despite the fact that we have controlled for a host of other explanatory factors. These barriers are likely to decline with age because individuals acquire investment skill over time, and also because the least costly way for modest households to invest in stocks is through retirement accounts, which are most popular for mature individuals.

Barriers to entry have historically prevented most individuals from owning stocks. However, the rapid growth of pooled funds and self-directed accounts in recent years have lowered the cost of entry. As a result, the fraction of stockholders in the population has increased over time not only unconditionally, as seen in the previous section, but has also increased after we controlled for other household characteristics, as evidenced by the rising 
pattern of the time dummies in Table 5. The probit regressions in Tables 5 and 6 are consistent with the entry cost argument in several other ways. First, as mentioned above, the late age at which the conditional likelihood of holding stocks peaks may be explained by entry barriers. Second, the positive coefficients for professional financial advice are consistent with informational costs being an entry barrier. ${ }^{11}$ Third, the positive relationship between financial net worth and the likelihood of owning stocks is indicative that only households with substantial wealth find it worthwhile to incur the entry costs. ${ }^{12}$ And fourth, the positive and large coefficients for the retirement saving motive is consistent with a costly acquisition of stocks for two reasons. Individuals who save for their retirement are more likely to hold retirement accounts, which reduce the cost of owning stocks. Also, these individuals are likely to have long investment horizons, so a one time cost of purchasing stocks should matter relatively little.

The negative and strongly significant coefficients for relative business value and investment in own business are consistent with the findings of Heaton and Lucas (2000), who emphasize that conditional on other demographic factors, entrepreneurial risk crowds out stock investment. Also, it is consistent with Faig and Shum (2002) who show that individuals engaged in relatively illiquid personal projects, such as a private business, are in general less tolerant to risk in their financial portfolios.

Tables 5 and 6 show a negative, but statistically insignificant relationship between exposure to real estate and the likelihood of holding stocks. Theoretically, this relationship is ambiguous because exposure to real estate affects the financial portfolio in a variety of ways. Not only is real estate a risky investment, but also it has special characteristics such as being illiquid, providing the consumption stream of shelter, and generating regular liquidity needs (e.g., mortgage, property tax, and utility payments, and maintenance costs). Because of all these complexities, the interaction between housing and the financial portfolio

11 The positive coefficient of professional advice could also be interpreted as stockholders being more likely to seek advice.

12 This positive relationship could also be the result of risk aversion declining with wealth 
is theoretically ambiguous. ${ }^{13}$ Empirically, both Kullman and Siegel (2003), using PSID data, and Curcuru, Heaton, Lucas, and Moore (2004), using SCF data, find, as we do, a negative relationship between stockholding and exposure to real estate. In their studies, this relationship is statistically significant. ${ }^{14}$

We also performed statistical tests to see if the influence of the explanatory variables changed significantly over time. The null hypothesis is that the difference in slope coefficient across time from the 1992 survey year is zero. The results can be summarized as follows. For the 1995 survey, the null cannot be rejected, and it is true for all of the explanatory variables. In other words, there was no statistically significant change in the slope of any of the explanatory variables. For the 1998 survey, the null cannot be rejected for all of the explanatory variables, except for relative business value: it lost its statistical significance in 1998. For the 2001 survey: the null cannot be rejected, except for three explanatory variables. These three variables have stronger effects with statistical significance in 2001: financial net worth, risk attitude, labour income (log of). Hence, the relationship between stock ownership and the various explanatory variables has been fairly stable over time, except for some wealth and risk measures in 2001.

\section{Equity shares in the portfolio}

Having studied the decision of whether or not to invest in stocks, the logical next step is to consider "how much", that is, the determinants of equity shares in the financial portfolio. To this end, we employ the same set of explanatory factors in a conditional linear regression. Only those households who own stocks are included in the sample. In Table 7 below, we report the results from the pooled data of the four surveys we study.

13 See Cocco (2005) and the references in Curucuru, Heaton, Lucas, and Moore (2004), Section 4.2. Also, see Banks, Blundell, and Smith (2004) for an in depth study of how U.K. and U.S. investors respond to incentives on their housing and stock investments.

14 In an earlier version of our paper, we did find statistical significance in exposure to investment real estate. However, after the Federal Reserves changed the definition of investment real estate in the SCF macros in 2004, this variable lost its explanatory power. 
[Table 7]

Unlike Ameriks and Zeldes (2001), we do find evidence of a hump-shaped age effect, conditional on stock ownership. ${ }^{15}$ The main difference between our empirical framework and theirs is the set of explanatory variables. While Ameriks and Zeldes focus exclusively on age and time in their regressions, we include a wide range of household characteristics in ours. Therefore, after controlling for household characteristics, age does seem to have an impact on the share of stocks in household portfolios. Stock holdings increase until around age 50 and then, conditional on the other variables in the regression, start to decrease.

Despite a few significant coefficients, the results in Table 7 indicate a great deal of noise in household asset allocations, as the average adjusted $R^{2}$ over the five implicates in the Survey is only 8.5 percent. This low $R^{2}$ is in line with earlier studies of portfolio formation (Heaton and Lucas, 2000, Faig and Shum, 2002, Ameriks and Zeldes, 2001). In addition to age and age $^{2}$, the variables that are statistically significant at the 5 percent level are: risk attitude, stakes in private business, the time dummies, and two saving motives "invest in own home" and "retirement". The parameter estimates of these variables all have the expected sign, in that a higher level of risk aversion, larger stakes in other risky assets (private business) lead to a smaller fraction of stocks in the financial portfolio, while this fraction increases with time. Further, those who are saving for retirement tend to allocate more of their financial portfolio to equities, and those who are saving to buy or renovate a home tend to allocate less to equities. ${ }^{16}$ The three time dummies are statistically significant and they are increasing over time. It is particularly interesting to observe that the 2001 dummy is even higher than the 1998 dummy. So at least until 2001 stockholders did not decrease their relative exposure to equities despite the end of the bullish climate of the nineties.

\footnotetext{
15 Ameriks and Zeldes (2001) find that conditional on stock ownership, the fraction held in equities is fairly constant with age. These results hold in both the SCF and TIAA-CREF data sets.

16 Faig and Shum (2002) provides a model in which households become more risk averse in their portfolio choice when they take on productive personal projects. Housing is one such example.
} 
The fit does not improve significantly when we run separate conditional regressions for the four surveys, so non-stationarity does not explain the low R2 in Table 7. Moreover, since these separate regressions have smaller sample sizes, fewer variables are statistically significant. Only risk attitude is consistently significant in all four regressions. Because the results are uninteresting and to conserve space, we do not present these regressions here.

The low $R^{2}$ in Table 7 suggests highly erratic choices made by households while forming their portfolio of financial assets. This heterogeneity is also emphasized in a recent survey of the literature by Curucuru, Heaton, Lucas, and Moore (2004), so it is consistent with alternative data sets and explanatory variables. Admittedly, survey data are known to be noisy. However, the SCFs are collected with great care, so noisy data are probably an incomplete explanation for the diverse and apparently erratic behavior we observe in household portfolio choice. A major challenge for modern theory of the portfolio choice is to develop more accurate explanations for the portfolios individuals form, or at least to rationalize why individual behavior is so erratic.

We also investigate whether having professional financial advice improves the predictability of equity allocations. We separate households with positive stock holdings into two subsamples: those who seek professional financial advice, and those who do not. Regression results from the two subsamples (not shown) are virtually indistinguishable. To confirm this finding, we run another regression, using the full sample of households with positive stock holdings, and add interaction terms between the explanatory factors and the

professional advice dummy variable. Indeed, none of the interaction terms are statistically significant at the five percent level except for one saving motive (household purchase).

\section{Tobit Analysis of equity holdings}

One may argue that it is more efficient to estimate the decision to hold equity and the share of equity in the portfolio jointly. Both Agnew, Balduzzi, and Sundén (2003) and Poterba and Samwick (2002) favour the Tobit specification for censored dependent 
variables. However, the factors that influence the two choices may be different, ${ }^{17}$ and strong parametric assumptions are used in the Tobit model. Ameriks and Zeldes (2001), for example, choose separate analyses of the two choices, as we do in the last two sections. In this section, we present our results from the Tobit regressions, as an alternative specification. In Table 8, we report the Tobit regression using the pooled data using the 1992, 1995, 1998, and 2001 surveys.

\section{[Table 8]}

The results from the Tobit analysis confirm those from the conditional linear analysis of the previous section. The significant coefficients at the 5 percent level in Table 8 are those that were significant in Table 7, except for the saving motive, invest in own home, which now is significant only at the 10.9 percent level. The sign of all coefficients is exactly the same in both tables. Also, we observe a hump-shaped age effect with a peak around 50 in both tables. As in the previous section, we ran separate regressions for each survey. Again, only risk attitude is consistently statistically significant in all four regressions. Variables such as relative business value and saving for retirement are significant only for one or two of the four years (not shown). Therefore, as before, pooling several years of data together is required to generate a reasonable story. Further, using the sample of individuals who sought financial investment advice yields almost identical results from the whole sample (not shown).

\section{Conclusion}

When we combine the analyses in the preceding sections, we reach the following conclusions. There is great heterogeneity in the way households form their financial portfolios. With available data we are able to explain only a small fraction of this diversity. We find that the decision to hold stocks is positively correlated with various measures of

\footnotetext{
17 For example, it is conceivable that for a group of individuals professional advise breaks the barriers to enter the stock market, but it reduces the exposure to stocks for those in the market by pointing to the risks of undiversified portfolios. This hypothetical case cannot be captured in a Tobit model.
} 
wealth, such as financial net worth and labour income, with age, with risk attitude, with having sought financial advice, and with some saving motives such as saving for retirement. Moreover, stock ownership is negatively correlated with holdings of alternative risky investments, such as private business, and with the willingness to undertake non-financial investments in the future, such as invest in own home and own business. Although we predict better who owns stocks than the portfolio shares for those that hold positive amounts, we find the following explanatory variables affect portfolio shares: age has a hump-shape effect with a peak around 50; financial net worth, time dummies, and saving for retirement have a positive effect; risk attitude and value of real investments (business or home) have a negative effect. Another noteworthy observation is that broadly-defined stocks - the dependent variable used in our study - respond more to the explanatory variables than narrowly-defined stocks (directly-held stocks, stocks held in mutual funds or thrift-type retirement accounts). This suggests that non-traditional forms of equity investment (stocks held in annuities, IRA/Keoghs, trusts and other managed investment accounts) are becoming more important in household portfolios.

A partial explanation for our findings is that, despite the advancement of internet technology in the last decade, there is still a significant barrier to equity investment for the average U.S. household, due to information and transaction costs. Unfortunately, this explanation is at best incomplete because it does not account for the wide diversity in the way households form their financial portfolios. This diversity may be due to a lack of understanding by investors of the true consequences of alternative investment strategies. That is, even if an individual has enough knowledge and confidence to buy stocks, he may not know how risky stocks are, or may not comprehend the advantages of diversification, or the need to rebalance his portfolio. If portfolio diversity is due to this reason, there is little we can do at this stage to better understand portfolio formation, except to emphasize the importance of financial education (although in the SCF data, we find that having sought professional investment advice does not improve the predictability of equity shares).

We believe that there are other important reasons - still not well understood - for 
portfolio diversity. For example, the precise environment in which consumption, saving, and investment decisions take place must matter a great deal on risk taking behavior. In our earlier paper (Faig and Shum, 2002), we show that the lumpiness and illiquidity of private investment projects change in surprising ways the risk taking behavior in the portfolio of financial assets. More generally, liquidity considerations and the lumpiness of many expenditures should affect the incentives for accepting risks in the financial portfolio in ways that we should strive to understand better.

Finally, several studies have reported that investors make extreme choices in their retirement and mutual fund accounts, and that this behavior may be tied to psychological factors. However, when we consider the equity share in their overall portfolios, such behavior is not evident. Hence, it is possible that the observed "zero or one" choice in these "subset" accounts are simply strategies to minimize total tax liabilities or transaction costs. 


\section{References}

[1] Agnew, Julie, Pierluigi Balduzzi, and Annika Sundén, 2003, "Portfolio Choice and Trading in Large 401(k) Plan," American Economic Review, 93, 193-215.

[2] Alexander, Gordon J., Jonathan D. Jones, and Peter J. Nigro, 1997, "Mutual Fund Shareholders: Characteristics, Investor Knowledge, and Sources of Information," Office of the Comptroller of the Currency Working Paper 97-13.

[3] Ameriks, John, and Stephen Zeldes, 2001, "How Do Household Portfolio Shares Vary with Age?," Working Paper, Columbia University, Graduate School of Business.

[4] Aizcorbe, Ana M., Arthur B. Kennickell and Kevin B. Moore, 2003, "Recent Changes in U.S. Family Finances: Evidence from 1998 and 2001 Survey of Consumer Finances," Federal Reserve Bulletin 89, 1-32.

[5] Banks, James, Richard Blundell, and James P. Smith, 2004, "Wealth Portfolios in the United Kingdom and the United States," in Perspectives on the Economics of Ageing, D. Wise (ed), National Bureau of Economic Research, 205-246.

[6] Barber, Brad M. and Terrance Odean, 2001, "Boys Will be Boys: Gender, Overconfidence, and Common Stock Investment," Quarterly Economic Review, 116, 261-292.

[7] Barberis, Nicholas, 2000, "Investing for the Long Run When Returns Are Predictable," Journal of Finance, vol.55-1, 225-264.

[8] Basak, S. and Cuoco, D. 1998, "An Equilibrium Model with Restricted Stock Market Participation," Review of Financial Studies, 11, 309-341.

[9] Bergstresser, Daniel and James Poterba, 2002, "Asset Allocation and Asset Location: Household Evidence from the Survey of Consumer Finances," Working Paper 9268, NBER.

[10] Bertaut, C. and M. Haliassos, 1997, "Precautionary Portfolio Behavior from a Life-Cycle Perspective," Journal of Economic Dynamics and Control, 21, 1511-1542.

[11] Canner, Niko, N. Gregory Mankiw and David N. Weil, 1997, "An Asset Allocation 
Puzzle," American Economic Review 91, 1-29.

[12] Cocco, Jo $\widetilde{o}$, 2004, "Porfolio Choice in the Presence of Housing," Review of Financial Studies, forthcoming.

[13] Cocco, João, Francisco J. Gomes, and Pascal J. Maenhout, 2005, "Consumption and Portfolio Choice Over the Life Cycle," Review of Financial Studies 18 (2): 491-533.

[14] Curcuru, Stephanie, John Heaton, Deborah Lucas, and Damien Moore, 2004, "Heterogeneity and Porfolito Choice: Theory and Evidence," manuscript prepared for the Handbook of Financial Econometrics.

[15] Faig, Miquel and Pauline M. Shum, 2002, "Portfolio Choice in the Presence of Personal Illiquid Projects," Journal of Finance 57, 303-328.

[16] Heaton, John, and Deborah Lucas, 1997, "Market Frictions, Savings Behavior, and Portfolio Choice," Macroeconomic Dynamics, 1, 76-101.

[17] Heaton, John and Deborah Lucas, 2000, "Portfolio Choice and Asset Prices: The Importance of Enterpreneurial Risk," Journal of Finance 55, 1163-1198.

[18] Kennickell, Arthur B., 1998, Multiple imputation in the survey of consumer finances, Working paper, SCF group, Federal Reserve Board.

[19] Koo, Hyeng-Keun, 1995, "Consumption and Portfolio Selection with Labor Income I:

Evaluation of Human Capital," Working Paper, Washington University.

[20] Kullmann, Cornelia, and Stephan Siegel, 2003, "Real Estate and its Role in Household Portfolio Choice," manuscript, University of British Columbia.

[21] Odean, Terrance, 1999, "Do Investors Trade Too Much," American Economic Review $89,1279-1298$.

[22] Paiella, Monica, 2001, "Limited Financial Market Participation: A Transaction Cost-Based Explanation," IFS Working Paper W01/06, Institute for Fiscal Studies. [23] Polkovnichenko, Valery, 2004, "Life Cycle Consumption and Portfolio Choice with Additive Habit Formation Preferences and Uninsurable Income Risk, manuscript, University of Minnesota, Carlson School of Management. 
[24] Poterba, James M. and Andrew A. Samwick, 2002, "Taxation and Household Portfolio Composition: US Evidence from the 1980s and 1990s," Journal of Public Economics, $87,5-38$.

[25] Saito, Makoto, 1995, "Limited Market Participation and Asset Pricing," manuscript, University of British Columbia, Department of Economics.

[26] Viceira, Luis M. 2001, "Optimal Portfolio Choice for Long-Horizon Investors with Non-Tradable Labor Income," Journal of Finance, 51, 433-470.

[27] Vissing-Jørgensen, Annette, 2004, "Perspectives on Behavioral Finance: Does "Irrationality" Disappear with Wealth? Evidence from Expectations and Actions," NBER Macroeconomics Annual 2003, edited by Mark Gertler and Kenneth Rogoff, The MIT Press: p. 139-194.

[28] Woolley, Matthew, 2004, "Optimal Consumption and Investment with Labor Income Uncertainty and Endogenous Retirement," manuscript, University of North Carolina at Chapel Hill. 
Table 1

\section{Distributions of Households by Equity Share in Financial Portfolio}

Share of stocks (in each category) in financial portfolio Total stock holdings

stocks $=0$

$0<$ stocks $<=0.2$

$0.2<$ stocks $<=0.4$

$0.4<$ stocks $<=0.6$

$0.6<$ stocks $<=0.8$

$0.8<$ stocks $<1$

stocks $=1$
Percentage of households

\begin{tabular}{ccccccccc}
\multicolumn{3}{c}{ Total stock holdings } & \multicolumn{3}{c}{$\begin{array}{c}\text { Stocks in retirement } \\
\text { accounts }\end{array}$} \\
& & & & & \\
$\mathbf{1 9 9 2}$ & $\mathbf{1 9 9 5}$ & $\mathbf{1 9 9 8}$ & $\mathbf{2 0 0 1}$ & $\mathbf{1 9 9 2}$ & $\mathbf{1 9 9 5}$ & $\mathbf{1 9 9 8}$ & $\mathbf{2 0 0 1}$ \\
41.99 & 40.12 & 30.03 & 27.97 & 57.88 & 52.08 & 42.99 & 38.88 \\
19.22 & 14.91 & 13.22 & 12.02 & 17.26 & 16.33 & 18.46 & 18.31 \\
14.17 & 12.91 & 13.08 & 13.65 & 11.18 & 11.85 & 13.39 & 15.73 \\
11.69 & 13.07 & 16.13 & 16.22 & 8.00 & 9.97 & 12.10 & 12.58 \\
6.34 & 9.77 & 12.41 & 11.78 & 2.72 & 5.48 & 6.39 & 6.27 \\
6.32 & 9.05 & 15.01 & 17.97 & 2.68 & 4.19 & 6.61 & 7.95 \\
0.27 & 0.16 & 0.12 & 0.39 & 0.27 & 0.11 & 0.06 & 0.29
\end{tabular}

\begin{tabular}{lrrrrrrrr} 
& \multicolumn{3}{c}{ Directly-held stocks } & \multicolumn{3}{c}{ Stocks in mutual funds } \\
& $\mathbf{1 9 9 2}$ & $\mathbf{1 9 9 5}$ & $\mathbf{1 9 9 8}$ & $\mathbf{2 0 0 1}$ & $\mathbf{1 9 9 2}$ & $\mathbf{1 9 9 5}$ & $\mathbf{1 9 9 8}$ & $\mathbf{2 0 0 1}$ \\
stocks $=0$ & 74.19 & 78.47 & 72.00 & 71.26 & 86.24 & 83.00 & 77.87 & 76.99 \\
$0<$ stocks $<=0.2$ & 15.59 & 13.80 & 15.30 & 17.06 & 9.35 & 9.78 & 11.78 & 13.31 \\
$0.2<$ stocks $<=0.4$ & 5.05 & 3.08 & 6.27 & 5.60 & 3.31 & 4.09 & 5.82 & 5.01 \\
$0.4<$ stocks $<=0.6$ & 3.08 & 2.50 & 3.21 & 3.08 & 0.86 & 1.95 & 2.72 & 2.97 \\
$0.6<$ stocks $<=0.8$ & 1.26 & 1.28 & 2.01 & 1.58 & 0.16 & 0.48 & 1.19 & 1.13 \\
$0.8<$ stocks $<1$ & 0.83 & 0.87 & 1.15 & 1.41 & 0.09 & 0.65 & 0.62 & 0.59 \\
stocks $=1$ & 0.00 & 0.00 & 0.06 & 0.00 & 0.00 & 0.06 & 0.00 & 0.00
\end{tabular}

Notes: Financial portfolio is the total value of financial assets held by a household. Retirement accounts include individual retirement accounts such as IRAs and Keoghs, as well as defined contribution plans such as thrift and 401(k) accounts. Directly-held stocks do not include stocks held in retirement accounts. Stock mutual funds are funds that are held outside retirement accounts. Sampling weights adjusted. 
Table 2

\section{Distributions of Households Who Sought Professional Investment Advice by Equity Share in Financial Portfolio}

\section{Share of stocks (in each category)} in financial portfolio Total stock holdings

$$
\text { stocks }=0
$$

$0<$ stocks $<=0.2$

$0.2<$ stocks $<=0.4$

$0.4<$ stocks $<=0.6$

$0.6<$ stocks $<=0.8$

$0.8<$ stocks $<1$

stocks $=1$

8.76

0.33
Percentage of households

Stocks in retirement accounts

$\begin{array}{lll}1995 & 1998 & 2001\end{array}$

$\begin{array}{lll}47.37 & 38.05 & 40.28\end{array}$

$20.24 \quad 22.50 \quad 20.19$

$\begin{array}{lll}13.26 & 14.61 & 16.85\end{array}$

$\begin{array}{lll}9.63 & 11.57 \quad 9.72\end{array}$

$\begin{array}{lll}6.24 & 6.50 \quad 5.32\end{array}$

$\begin{array}{lll}3.22 & 6.77 & 7.58\end{array}$

$\begin{array}{lll}0.06 & 0.00 & 0.06\end{array}$

Stocks in mutual funds

$$
\text { stocks }=0
$$

$0<$ stocks $<=0.2$

$16.60 \quad 18.97$

$0.04 \quad 0.06$

Directly-held stocks

$0.2<$ stocks $<=0.4$

16.38

1995

1998

2001

$73.82 \quad 66.86$

69.77

18.63

17.71

7.11

5.87

$3.82 \quad 3.59$

3.90

2.57

1.73

1.33

0.97

1.33

0.34

0.04

0.00

0.00

\begin{tabular}{rrr}
\multicolumn{3}{c}{ Stocks in mutual } \\
funds \\
$\mathbf{1 9 9 5}$ & $\mathbf{1 9 9 8}$ & $\mathbf{2 0 0 1}$ \\
72.15 & 73.45 & 73.34 \\
15.81 & 13.91 & 15.74 \\
6.79 & 7.31 & 6.13 \\
3.32 & 3.19 & 3.53 \\
0.37 & 1.24 & 0.78 \\
1.27 & 0.90 & 0.48 \\
0.28 & 0.00 & 0.00
\end{tabular}

0.00

Notes: Professional investment advice includes advice from financial planners, brokers, accountants, and/or bankers. This variable was introduced in the 1995 survey. The fractions of households who sought professional investment advice are: 26 percent in 1995, 37 percent in 1998 and 36 percent in 2001. See also notes to Table 1. 
Table 3

\section{Distribution of Households by Equity Shares in} Retirement Accounts and Mutual Funds Accounts

\begin{tabular}{|c|c|c|c|c|c|c|c|c|}
\hline \multirow{3}{*}{$\begin{array}{l}\text { Share of stocks in } \\
\text { each type of account }\end{array}$} & \multicolumn{8}{|c|}{ Percentage of households } \\
\hline & \multicolumn{4}{|c|}{ Retirement accounts } & \multicolumn{4}{|c|}{ Mutual funds accounts } \\
\hline & 1992 & 1995 & 1998 & 2001 & 1992 & 1995 & 1998 & 2001 \\
\hline stocks $=0$ & 33.49 & 31.01 & 20.44 & 17.42 & 36.14 & 24.52 & 20.33 & 21.20 \\
\hline$<$ stocks $<=0.2$ & 5.35 & 5.31 & 3.55 & 2.76 & 5.91 & 4.94 & 2.20 & 2.99 \\
\hline $.2<$ stocks $<=0.4$ & 8.05 & 5.95 & 5.13 & 4.87 & 7.16 & 6.41 & 5.18 & 4.54 \\
\hline $.4<$ stocks $<=0.6$ & 22.94 & 19.97 & 23.85 & 21.51 & 17.05 & 11.15 & 9.23 & 9.38 \\
\hline $0.6<$ stocks $<=0.8$ & 3.82 & 4.76 & 4.76 & 5.58 & 6.79 & 8.22 & 8.32 & 9.15 \\
\hline $0.8<$ stocks $<1$ & 4.01 & 4.44 & 4.77 & 5.90 & 3.72 & 8.00 & 10.45 & 8.68 \\
\hline tocks $=1$ & 22.34 & 28.57 & 37.49 & 41.97 & 23.24 & 36.76 & 44.30 & 44.06 \\
\hline
\end{tabular}

Notes: The sample for retirement accounts includes only households with at least one retirement account. Similarly, the sample for mutual funds accounts includes only households with at least one mutual funds account. Retirement accounts includes individual retirement accounts such as IRAs and Keoghs, as well as defined contribution plans such as thrift and 401(k) accounts. Mutual funds accounts do not include mutual funds held in retirement accounts. Sampling weight adjusted. 
Table 4

Distribution of Households Who Sought Professional Investment Advice by Equity Shares in Retirement Accounts and Mutual Funds Accounts

Share of stocks in

Percentage of households

\begin{tabular}{lrrrrrr} 
each type of account & \multicolumn{3}{c}{ Retirement accounts } & \multicolumn{3}{c}{ Mutual funds accounts } \\
& $\mathbf{1 9 9 5}$ & $\mathbf{1 9 9 8}$ & $\mathbf{2 0 0 1}$ & $\mathbf{1 9 9 5}$ & $\mathbf{1 9 9 8}$ & $\mathbf{2 0 0 1}$ \\
stocks $=0$ & 29.85 & 16.82 & 22.29 & 21.82 & 19.26 & 23.83 \\
$0<$ stocks $<=0.2$ & 6.13 & 3.90 & 2.35 & 4.63 & 2.43 & 3.99 \\
$0.2<$ stocks $<=0.4$ & 5.34 & 6.62 & 4.69 & 4.73 & 5.10 & 5.13 \\
$0.4<$ stocks $<=0.6$ & 16.56 & 24.65 & 20.51 & 12.58 & 11.07 & 10.90 \\
$0.6<$ stocks $<=0.8$ & 6.33 & 4.35 & 4.37 & 9.03 & 7.89 & 9.07 \\
$0.8<$ stocks $<1$ & 2.99 & 5.46 & 6.13 & 10.29 & 10.62 & 9.83 \\
stocks $=1$ & 32.80 & 38.21 & 39.67 & 36.92 & 43.62 & 37.25
\end{tabular}

Note: See notes to Tables 2 and 3. 


\section{Table 5}

\begin{tabular}{|c|c|c|}
\hline & Coefficient & P-value \\
\hline Intercept & $-1.4537^{*}$ & 0 \\
\hline Age & $0.0293^{*}$ & 0.0003 \\
\hline $\mathrm{Age}^{2}$ & $-0.0002^{*}$ & 0.0038 \\
\hline Financial net worth & $0.0001^{*}$ & 0 \\
\hline Financial net worth ${ }^{2}$ & $-2.9 \mathrm{E}-10^{*}$ & 0 \\
\hline Relative housing value & -0.0048 & 0.8319 \\
\hline Investment real estate & 0.0173 & 0.8249 \\
\hline Risk attitude & $-0.3768^{*}$ & 0 \\
\hline Relative business value & $-0.0786^{*}$ & 0.0196 \\
\hline Log of labour income & $0.1803^{*}$ & 0 \\
\hline 1995 survey & 0.0075 & 0.8580 \\
\hline 1998 survey & $0.1121^{*}$ & 0.0084 \\
\hline 2001 survey & $0.2191^{*}$ & 0 \\
\hline \multicolumn{3}{|l|}{ Saving motives: } \\
\hline Education & $0.1631^{*}$ & 0.0001 \\
\hline Invest in own home & -0.0936 & 0.1460 \\
\hline Household purchases & $0.1950^{*}$ & 0.0089 \\
\hline Travel & 0.0402 & 0.4872 \\
\hline Invest in own business & $-0.3462^{*}$ & 0.0462 \\
\hline Retirement & $0.3556^{*}$ & 0 \\
\hline Emergency & 0.0404 & 0.2126 \\
\hline Living expenses and bills & 0.0921 & 0.2453 \\
\hline
\end{tabular}

\begin{tabular}{ll}
\hline \hline Log likelihood & -5040.04 \\
Accordant responses (\%) & 78 \\
Pseudo $R^{2}$ & 0.1749
\end{tabular}

Note: Stocks refer to total stock holdings. Model estimated using the RepeatedImputation Inference (RII) technique (see Montalto and Sung, 1996). An asterisk indicates significantly different from zero at the 5 percent level. Log likelihood, accordant responses, and pseudo $R^{2}$ are averages over the five implicates in the surveys. 
Table 6

\section{Probit Analysis: The Decision to Hold Stocks \\ SCF 1992, 1995, 1998, and 2001}

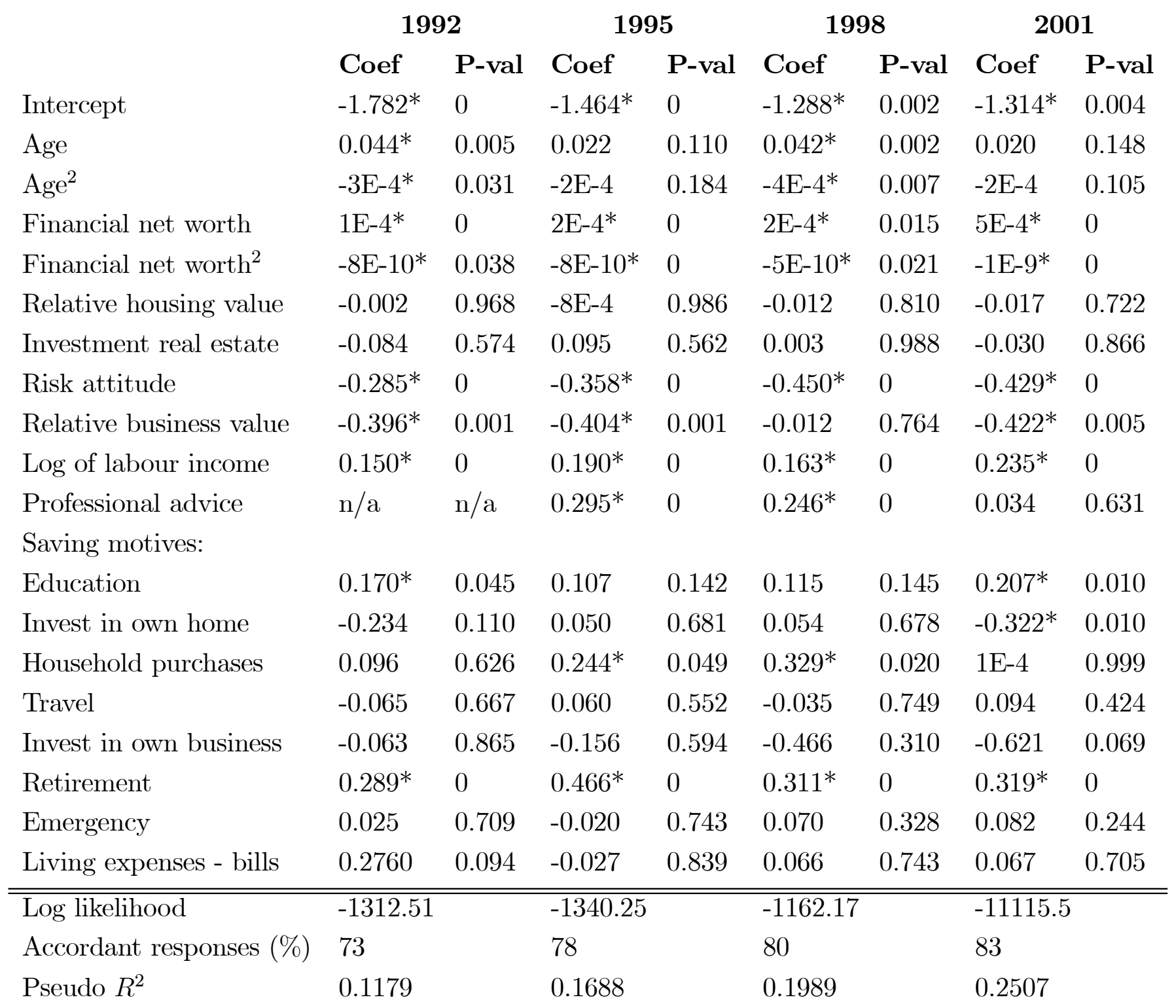

Note: See notes to Table 5. 
Table 7

Conditional Linear Regression: Explaining Equity Shares

Pooled Data (SCF 1992, 1995, 1998, and 2001)

Coefficient $\mathbf{P}$-value

\begin{tabular}{|c|c|c|}
\hline Intercept & $0.4532^{*}$ & 0 \\
\hline Age & $0.0041^{*}$ & 0.0194 \\
\hline $\mathrm{Age}^{2}$ & $-4.0 \mathrm{E}-5^{*}$ & 0.0174 \\
\hline Financial net worth & $1.6 \mathrm{E}-6^{*}$ & 0.0054 \\
\hline Financial net worth ${ }^{2}$ & $-2.3 \mathrm{E}-12$ & 0.2895 \\
\hline Relative housing value & -0.0004 & 0.9517 \\
\hline Investment real estate & -0.0411 & 0.0767 \\
\hline Risk attitude & $-0.0678^{*}$ & 0 \\
\hline Relative business value & $-0.0582^{*}$ & 0 \\
\hline Log of labour income & 0.0041 & 0.1622 \\
\hline 1995 survey & $0.0497^{*}$ & 0 \\
\hline 1998 survey & $0.1168^{*}$ & 0 \\
\hline 2001 survey & $0.1267^{*}$ & 0 \\
\hline \multicolumn{3}{|l|}{ Saving motives: } \\
\hline Education & 0.0044 & 0.5869 \\
\hline Invest in own home & $-0.0499 *$ & 0.0073 \\
\hline Household purchases & 0.0149 & 0.3688 \\
\hline Travel & -0.0048 & 0.7166 \\
\hline Invest in own business & -0.0679 & 0.1506 \\
\hline Retirement & $0.0216^{*}$ & 0.0037 \\
\hline Emergency & -0.0150 & 0.0666 \\
\hline Living expenses and bills & -0.0209 & 0.2539 \\
\hline
\end{tabular}

Note: Equity refers to total stock holdings. Model estimated using the RepeatedImputation Inference (RII) technique (see Montalto and Sung, 1996). An asterisk indicates a coefficient is significantly different from zero at the 5 percent level. The average adjusted $R^{2}$ over the five implicates is 8.6 percent. 


\section{Table 8}

\begin{tabular}{|c|c|c|}
\hline \multicolumn{3}{|c|}{$\begin{array}{l}\text { Tobit Analysis: Equity Shares in Financial Portfolio } \\
\text { Pooled Data (SCF 1992, 1995, 1998, and 2001) }\end{array}$} \\
\hline & Coefficient & P-value \\
\hline Intercept & $-0.7054^{*}$ & 0 \\
\hline Age & $0.0078^{*}$ & 0.0521 \\
\hline $\mathrm{Age}^{2}$ & $-8.0 \mathrm{E}-5^{*}$ & 0.0396 \\
\hline Financial net worth & $2.8 \mathrm{E}-6^{*}$ & 0.0179 \\
\hline Financial net worth ${ }^{2}$ & $-5.9 \mathrm{E}-12$ & 0.1928 \\
\hline Relative housing value & -0.0068 & 0.6299 \\
\hline Investment real estate & -0.0979 & 0.0682 \\
\hline Risk attitude & $-0.1197^{*}$ & 0 \\
\hline Relative business value & $-0.1141^{*}$ & 0.0005 \\
\hline Log of labour income & 0.0070 & 0.2778 \\
\hline 1995 survey & $0.1106^{*}$ & 0 \\
\hline 1998 survey & $0.2195^{*}$ & 0 \\
\hline 2001 survey & $0.2388^{*}$ & 0 \\
\hline \multicolumn{3}{|l|}{ Saving motives: } \\
\hline Education & 0.0015 & 0.9368 \\
\hline Invest in own home & $-0.0961^{*}$ & 0.0280 \\
\hline Household purchases & 0.0244 & 0.5204 \\
\hline Travel & -0.0181 & 0.5544 \\
\hline Invest in own business & -0.1749 & 0.1081 \\
\hline Retirement & 0.0276 & 0.1090 \\
\hline Emergency & -0.0327 & 0.0775 \\
\hline Living expenses and bills & -0.0381 & 0.3739 \\
\hline Log likelihood & -9770.08 & \\
\hline
\end{tabular}

Note: Equity refers to total stock holdings. Model estimated using the RepeatedImputation Inference (RII) technique (see Montalto and Sung, 1996). An asterisk indicates a coefficient is significantly different from zero at the 5 percent level. The log likelihood and the pseudo $R^{2}$ are averages over the five implicates in the surveys. 